\title{
ANÁLISIS MORFOLÓGICO DEL TEJIDO URBANO FUNDACIONAL DE MEXICALI hacia una planeación conjunta
}

\author{
Alejandro José Peimbert Duarte \\ Berenice Vizcarra \\ Universidad Autónoma de Baja California \\ alejandro.peimbert@uabc.edu.mx \\ luz.vizcarra@uabc.edu.mx
}

\section{RESUMEN}

Mexicali cuenta con tres zonas interconectadas, limítrofes con la línea fronteriza entre México y EUA. Aun con diferencias notables, estas comparten ciertas características y problemáticas urbanas; en conjunto, constituyen un umbral urbano potencial y demandan un trabajo de recuperación simultáneo. Se trata de la zona del Río Nuevo, el barrio de Pueblo Nuevo y el Centro Histórico.

El objetivo es analizar las condiciones morfológicas que exigen que este tejido urbano fundacional sea abordado por la planeación a partir de una estrategia rigurosamente integral, evitando su análisis como zonas aisladas y entendiéndolo como un transecto urbano.

La metodología se inscribe en un cruce disciplinario entre sociología urbana, estudios culturales e historia urbana. Así, el análisis morfológico que se plantea incluye el estudio del paisaje a través de sus elementos culturales, sus funciones urbanas y su transformación histórica.

PALABRAS CLAVE: frontera, centro urbano, morfología urbana

\begin{abstract}
Mexicali has three interconnected zones, adjoining the border between Mexico and the United States. Although different from each other, they share certain characteristics and urban problems; together, they constitute a potential urban threshold and demand a simultaneous recovery work. They are the area of the New River, the neighborhood of Pueblo Nuevo and the Old Town.

The aim of the work is to analyze the morphological conditions that demand that this pioneer urban fabric be addressed by planning based on a rigorously integrated strategy, avoiding its analysis as isolated areas and understanding it as an urban transect.
\end{abstract}

The methodology is part of a disciplinary intersection between urban sociology, cultural studies and urban history. Thus, the morphological analysis that is proposed includes the study of the landscape through its cultural elements, its urban functions and its historical transformation.

KEYWORDS: border, downtown, urban morphology 


\section{INTRODUCCIÓN}

El Centro Histórico de Mexicali ha sido -desde su fundación- uno de los puntos con mayor tránsito en la ciudad, la ubicación del principal cruce fronterizo ha sido determinante para que esta zona continúe activa. La vecina ciudad de Calexico, en California, nació al mismo tiempo. Su trazado urbano y sus tipologías arquitectónicas lo evidencian. Por su parte, la zona del Río Nuevo es un borde urbano caracterizado por sus contrastes. Mientras se erigen a todo lo largo de su extensión, de forma desarticulada y dispersa, las más nuevas piezas arquitectónicas para el equipamiento público, se asoma también una imagen que advierte deterioro, riesgos e informalidad. A su vez, el barrio de Pueblo Nuevo es una de las primeras colonias habitacionales de Mexicali. Su desarrollo dilatado fue acompañado de pequeños comercios y escuelas de educación básica. A estas tres zonas no sólo las vincula su proximidad, sino la historia, las prácticas cotidianas, las rutas de quienes pueblan ahí, los mitos o las conexiones familiares. Este tejido urbano fundacional será tratado en este trabajo como el sector central de Mexicali.

Actualmente, la reubicación de la garita vehicular, proyecto en proceso en la zona del Río Nuevo, induce especulaciones para las primeras manzanas de la ciudad, en donde el comercio y los servicios se resisten al decaimiento. La zona del Río Nuevo funciona como un eje vial bien conectado, pero pudiera representar la barrera más contundente respecto a la segregación socio-espacial; ahí se sitúa la arquitectura pública más reciente, pero destaca también la construcción informal sobre asentamientos irregulares. La desocupación latente y progresiva desde hace casi dos décadas hacen que el barrio de Pueblo Nuevo luzca hoy en día desolado; es un territorio en el cual se asoman paulatinamente construcciones deshabitadas o baldíos expectantes ante un futuro inmobiliario incierto.

El objetivo de este trabajo es analizar las condiciones morfológicas que exigen que el tejido urbano fundacional de la ciudad de Mexicali, conformado por el Centro Histórico, Pueblo Nuevo y el Río Nuevo, sea abordado por la planeación urbana a partir de una estrategia rigurosamente conjunta, entendiéndolo como un solo sector central. La metodología de este trabajo se inscribe en una intersección disciplinaria de la que participan principalmente la sociología urbana, los estudios culturales y la historia urbana. Así, el análisis morfológico que se plantea incluye el estudio del paisaje a través de sus elementos culturales, sus funciones urbanas y su transformación histórica.

El texto inicia con una revisión de los aspectos históricos que atañen a la morfología urbana del tejido originario. Subrayando las diferencias que tanto el centro histórico de la ciudad, como sus zonas aledañas difieren respecto a la manera en la que se concibieron y desarrollaron las estructuras de los primeros cuadros en ciudades situadas en las regiones del centro y sur de México, o en diversas capitales de Latinoamérica. Muchas de ellas regidas por el trazo de la ciudad virreinal. En este sentido, la estrecha relación con los Estados Unidos fue determinante para la definición de la forma de la ciudad.

También, se trata el origen del barrio predominantemente habitacional de Pueblo Nuevo, destacando no solo cómo y quiénes lo fueron poblando, sino qué circunstancias motivaron el surgimiento de un enclave dependiente de la ciudad, pero desvinculado por la topografía, por su función y por el estrato socioeconómico de sus pioneros.

El Río Nuevo representa un elemento sumamente relevante para la historia de la ciudad. Su existencia ha incidido no solamente en la transformación de los primeros cuadros de la ciudad, sino en las características de la mancha urbana actual. Su presencia como marca geográfica transfronteriza, los desastres antropogénicos que ha provocado y las decisiones que se han tomado sobre su uso son relevantes también para el historia de la forma urbana.

Posteriormente, se expone la problemática urbana actual del sector central de Mexicali. Aunque se explican los fenómenos que afectan a cada una de las tres zonas, presentándolas por separado, en el texto se van enlazando a partir de escenarios comunes. La forma atípica del centro histórico, el despoblamiento del barrio de Pueblo Nuevo y un Río Nuevo condenado a ser un espacio inacabado: malestares que al conjugarse conforman un sector central obsoleto.

Finalmente, se analiza el marco institucional que ha incidido -más recientemente- en la planeación urbana de cada zona. Con ello, se pone en evidencia que las políticas de desarrollo urbano locales no se han encargado de abordar al sector de forma integrada, considerando así la co-dependencia en sus funciones, la vinculación en su estructura y el potencial como un nuevo corazón de ciudad. 


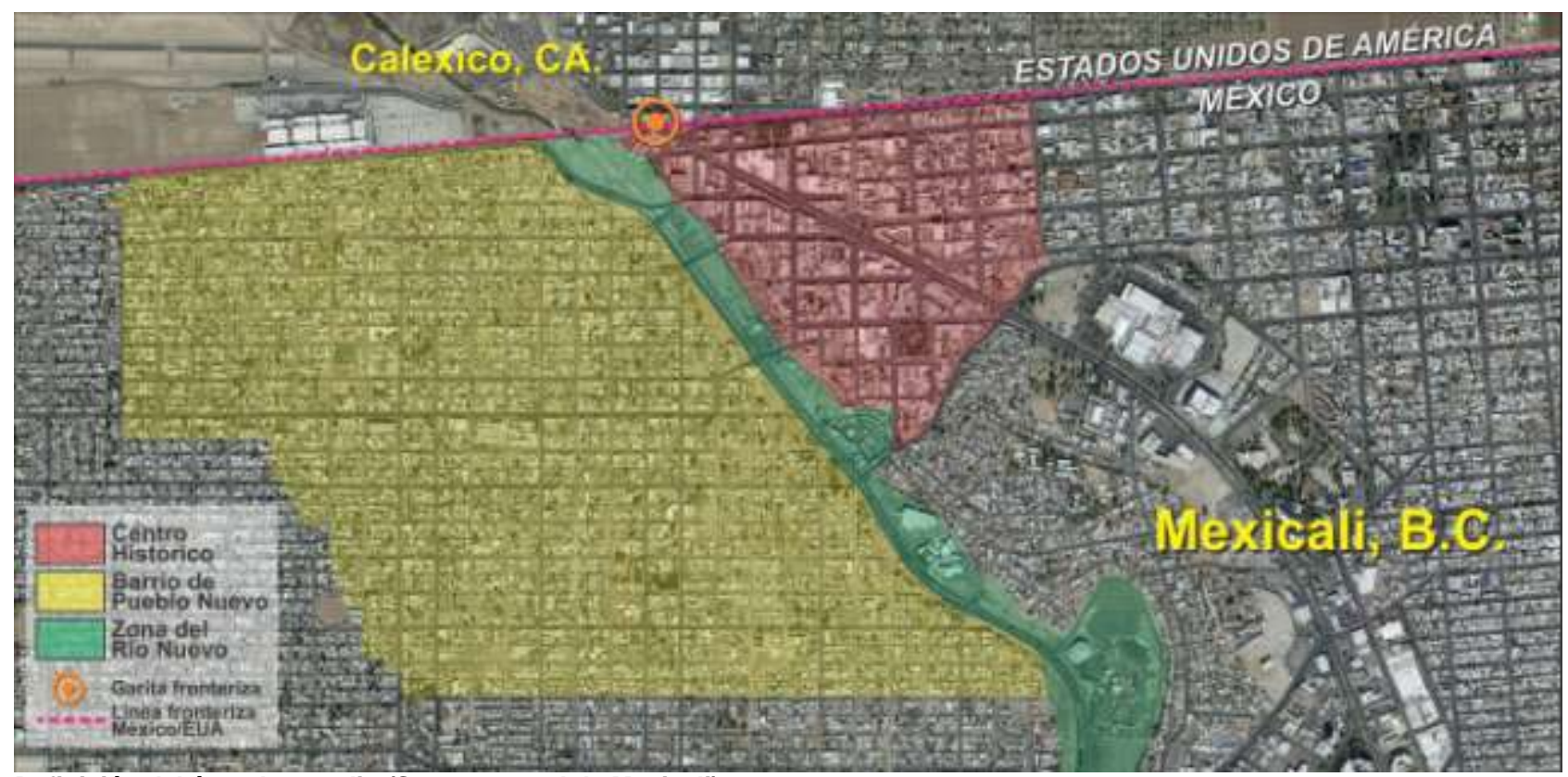

Definición del área de estudio (Sector central de Mexicali).

Elaboración propia sobre imagen satelital de Google Maps, 2018.

\section{HISTORIA DE LA FORMA URBANA DEL SECTOR CENTRAL DE MEXICALI}

La historia urbana de las ciudades de la frontera norte de México difiere en gran medida de la rigurosa fundación de las ciudades virreinales en el país o el resto de Latinoamérica. Estas no nacen o se reconstruyen del siglo XVI ó XVII, sino de un tardío siglo XIX o un temprano siglo XX; estas no se constituyen alrededor una plaza central, resguardada por templos (generalmente la catedral), mercados y edificios gubernamentales; estas no están trazadas de acuerdo al decreto de un imperio europeo, por el contrario, se ven íntimamente influenciadas por la planificación urbana de las ciudades norteamericanas.

Particularmente, la ciudad de Mexicali toma como fecha de fundación el día 14 de marzo de 1903, por ser este el día en que Jesús Manuel Vizcarra Orozco es nombrado primer Juez Auxiliar. Sin embargo, el establecimiento y morfología del centro fundacional de Mexicali, distan de esta arbitraria fecha.

Ya desde los últimos años del siglo XIX, un grupo de caseríos se había reunido en los parajes que hoy día forman el caso de estudio (es decir, entre la Primera y Tercera Sección), con motivo del proyecto hídrico de la California Development Co., encabezado por el ingeniero norteamericano Charles Rockwood, mismo que tenía como propósito canalizar las aguas del territorio mexicano e irrigar las nuevas plantaciones en el área conocida como Imperial Valley (o Valle Imperial) en California, Estados Unidos.

Aquí se funda la sociedad mexicalense, basada por varias décadas en una economía agrícola, formada por gente que, en busca de trabajo, migraba de distintas regiones del centro y sur de México, de localidades situadas en los Estados Unidos, e incluso de países lejanos como China o Rusia.

La historia de la morfología urbana que da origen al trazo actual comienza ya entrado el siglo XX, cuando entre 1905 y 1907 la demanda de agua para los campos agrícolas del Valle Imperial, aunado a un sistema hidráulico inadecuado, provocaron una serie de crecidas incontrolables en el cauce del canal Álamo, al oeste del Valle de Mexicali, prolongándose hasta el Río Nuevo, aledaño al naciente poblado. Sobre ello, Reyes explica en su tesis "La zona del río Nuevo como elemento de integración urbana entre el primer cuadro de la ciudad y la colonia Pueblo Nuevo":

El estancamiento de las aguas del río Nuevo amenazaban desaparecer las poblaciones de Mexicali y Calexico [asentamiento símil en California]; se intentó acelerar el paso de la corriente mediante el empleo de explosivos, pero su utilización en lugar de cumplir dicha tarea, inesperadamente acusó que el río cambiara se curso, formando el actual barranco y llevándose consigo no sólo la mitad del entramado urbano, sino los vestigios de las construcciones que conformaron lo que hoy es Mexicali. (1985: 31) 
Es esta la cicatriz que hoy por hoy divide a la ciudad tanto geográfica como socialmente: el barranco del Río Nuevo, única depresión en el llano Mexicali. Es un elemento que, junto con las vías del ferrocarril, atraviesa y le da forma a la explosiva expansión urbana.

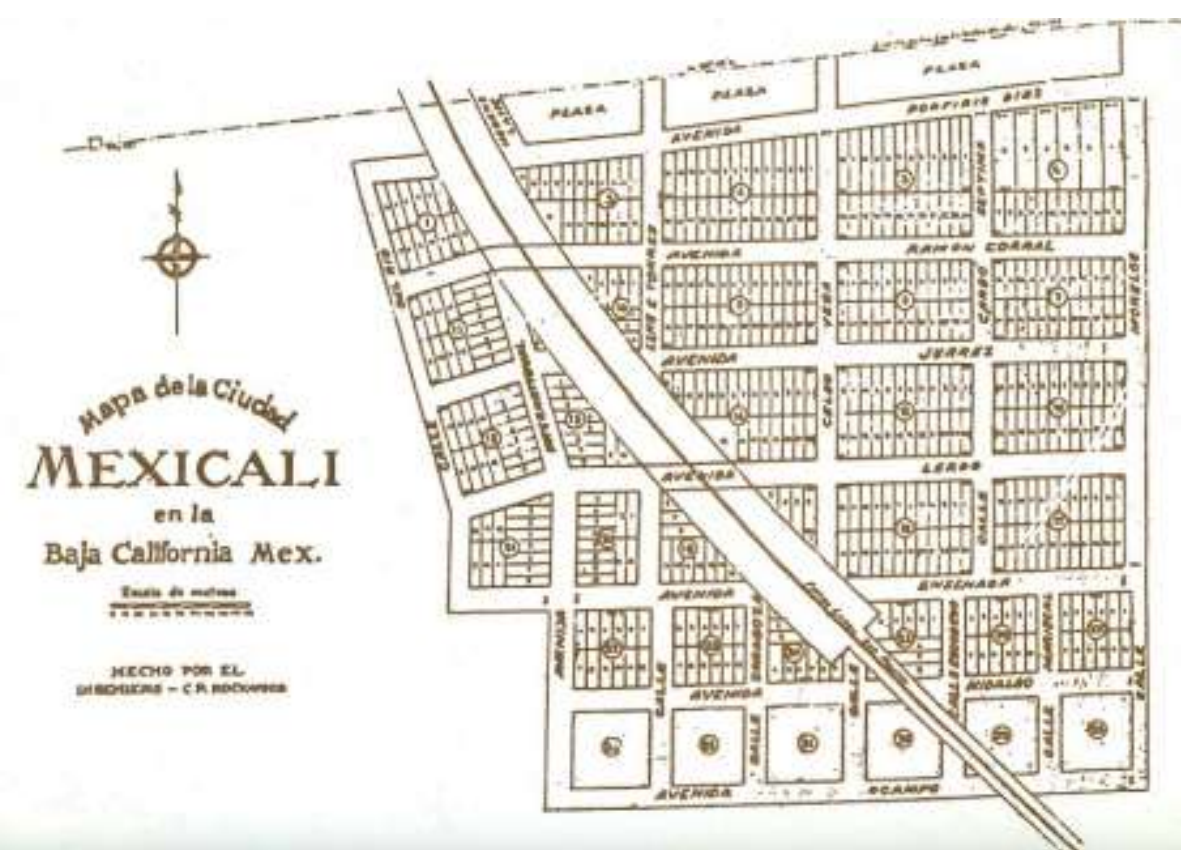

Mapa de la ciudad de Mexicali (traza modificada después de la gran inundación), según plano realizado por el Ing. Rockwood en 1902

Archivo Histórico de Mexicali.

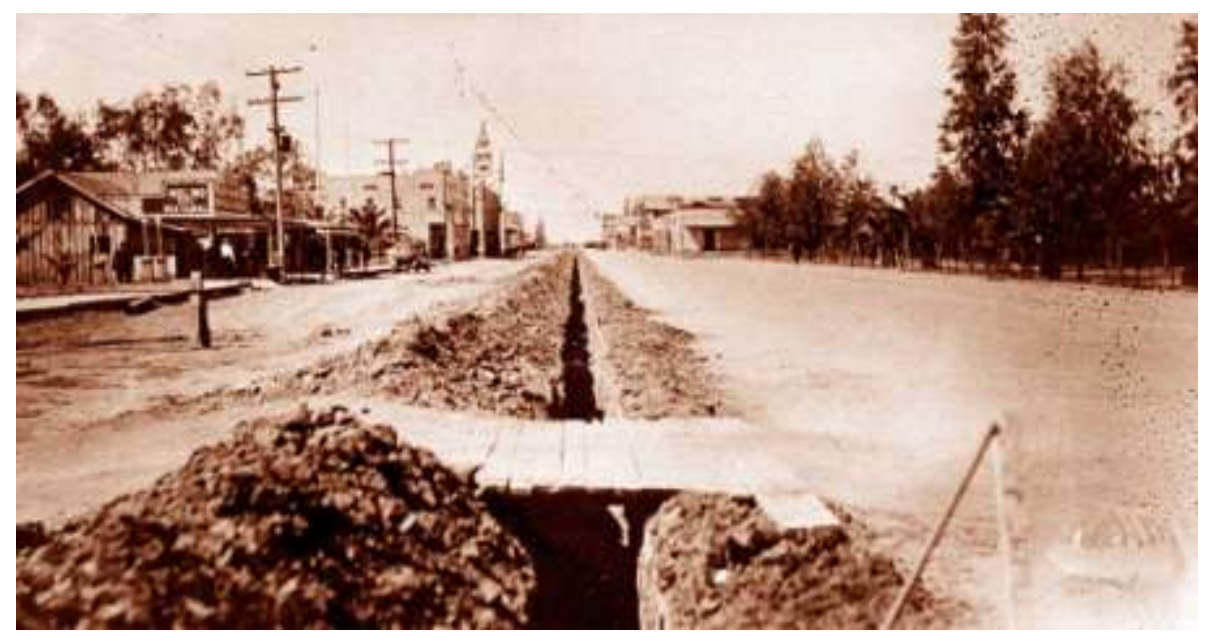

Avenida Porfirio Díaz (actualmente Francisco I. Madero). Circa 1910.

Archivo Histórico de Mexicali.

A partir de este evento, comienza a reconstituirse el centro fundacional de Mexicali, ciudad delimitada al norte por la línea fronteriza y al suroeste por el Río Nuevo. La traza urbana de la también conocida Primera Sección corresponde a la labor del ingeniero Charles R. Rockwood, que contemplaba la garita internacional, parques, corredores comerciales y zonas habitacionales sobre manzanas semi-ortogonales orientadas de norte a sur, todo ello tanto en Mexicali como en Calexico, ciudad hermana.

Conforme las asperezas del incidente hídrico pasaban y la población se iba restableciendo, también comenzaron a instalarse los servicios básicos de infraestructura y equipamiento, como escuelas y bancos, 0 puentes y carreteras de conexión.

A la usanza norteamericana, estas manzanas suelen estar divididas por callejones de servicio, lo que proporcionaba un submundo dentro de la propia ciudad. Así lo demuestran las leyendas de La Chinesca, míticos escondites entre callejones y sótanos en donde la sociedad de origen Chino lograba resguardarse; y 
lo continúan demostrando los inmuebles olvidados que -sorpresivamente- reaparecen ante los ojos de los mexicalenses cuando se realiza cualquier tipo de modificación al edificio con cara a la avenida principal y deja entrever los vestigios del Mexicali antiguo.

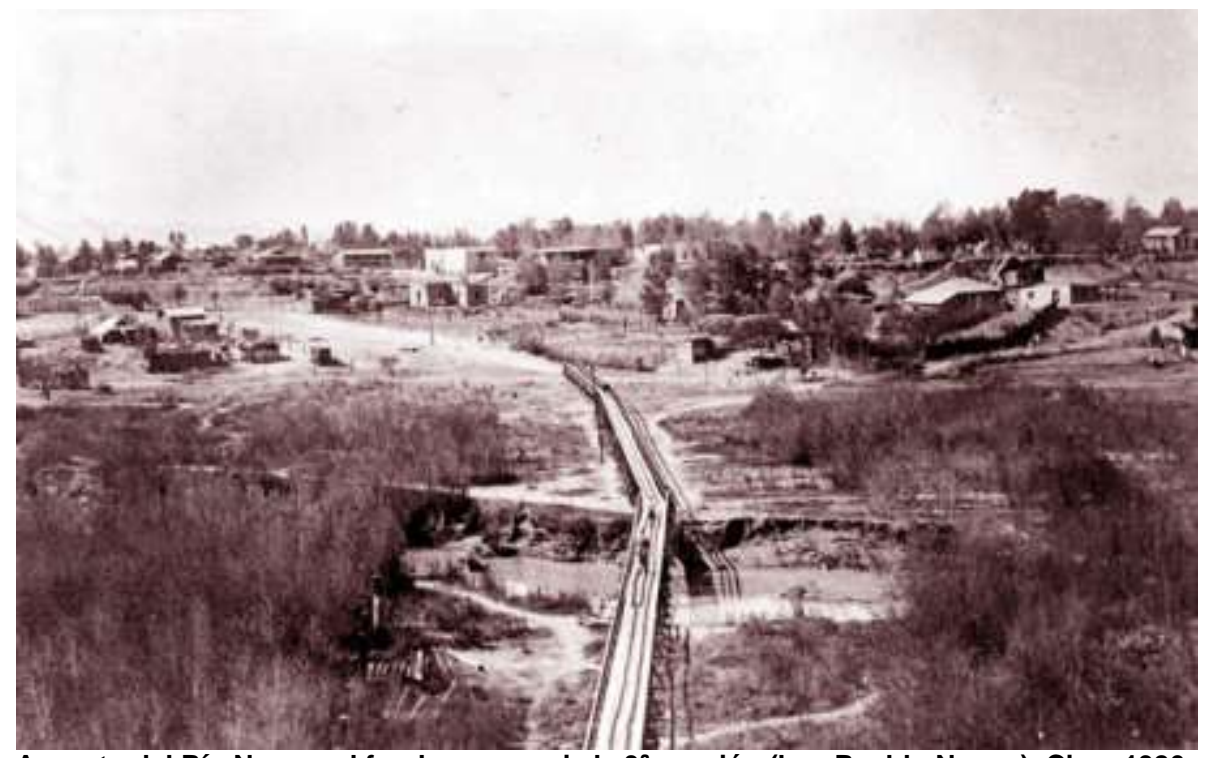

Aspecto del Río Nuevo, al fondo se aprecia la 3a sección (hoy Pueblo Nuevo). Circa 1926. Archivo Histórico de Mexicali.

Mientras el centro fundacional de Mexicali se consolidaba, el aumento poblacional de clase obrera provocó la conformación de un sub-centro habitacional al cual se le denominó Tercera Sección pero que comúnmente se le nombraba Pueblo Nuevo, justo por ser esto: un nuevo pueblo que se constituía de manera irregular al lado oeste del barranco del Río Nuevo.

Así, en los años previos a 1920 el Coronel Esteban Cantú, entonces gobernador del Distrito Norte (ahora estado de Baja California), encabezó un nuevo proyecto urbano que implicaba la adquisición, regularización, trazado, deslinde y repartición de dichos terrenos; estos, también se disponen de norte a sur con callejones de servicios, pero resultan mucho más ortogonales que los ubicados en la Primera Sección y con calles y avenidas más estrechas.

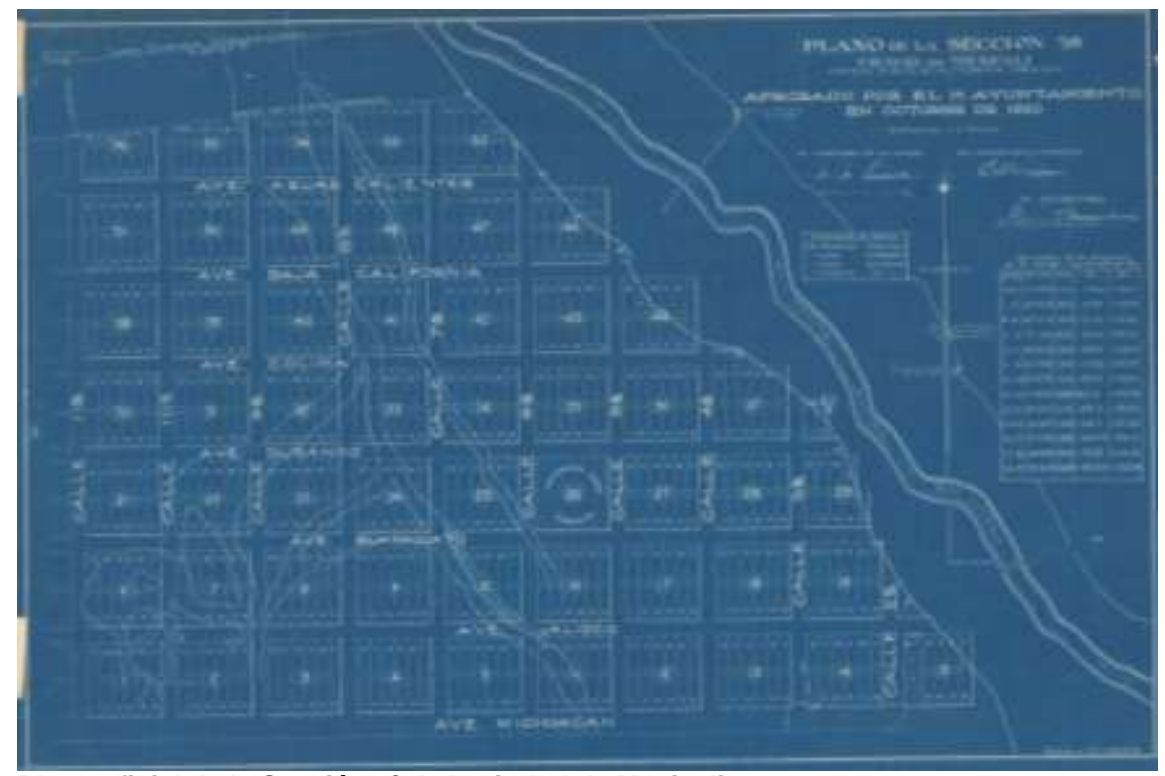

Plano oficial de la Sección $3^{a}$ de la ciudad de Mexicali

(posteriormente Ilamada Colonia Pueblo Nuevo) de 1920.

Mapoteca Nacional de México.

Este proyecto inició con 56 manzanas, una escuela rural y un corredor comercial como límite sur, siendo el resto -en su mayoría- uso de suelo habitacional. Sin embargo, en poco menos de una década la colonia 
duplicó su proporción, quedando entonces delimitada al norte por el borde fronterizo, al este por el barranco del Río Nuevo y al sur por el Camino Nacional, vialidad federal con destino a la ciudad de Tijuana. Es así como se constituyeron las bases en la morfología urbana de Mexicali, concentrándose la población obrera al poniente del Río Nuevo y estableciéndose los poderes políticos y económicos al oriente.

Durante décadas, la mancha urbana continuó con un crecimiento estable y sin grandes modificaciones en su estructura, no siendo hasta la década de 1970 cuando se presentan una serie de eventos que transformaran drásticamente a la ciudad. Entre las más relevantes se encuentra el cambio de sede del poder ejecutivo, legislativo y judicial de esta capital, situado originalmente en la Segunda Sección en el perímetro noreste, hacia el nombrado Centro Cívico y Comercial, ubicado en la continuidad sur del Río Nuevo. Así también, destaca la transformación de la actividad económica primaria que pasó del sector agrícola a la industria manufacturera, lo que en términos urbanos constituyó un crecimiento explosivo del área urbana de 6,236 ha. en 1960, a 15,600 ha. para el 2013 (IMIP, 2013).

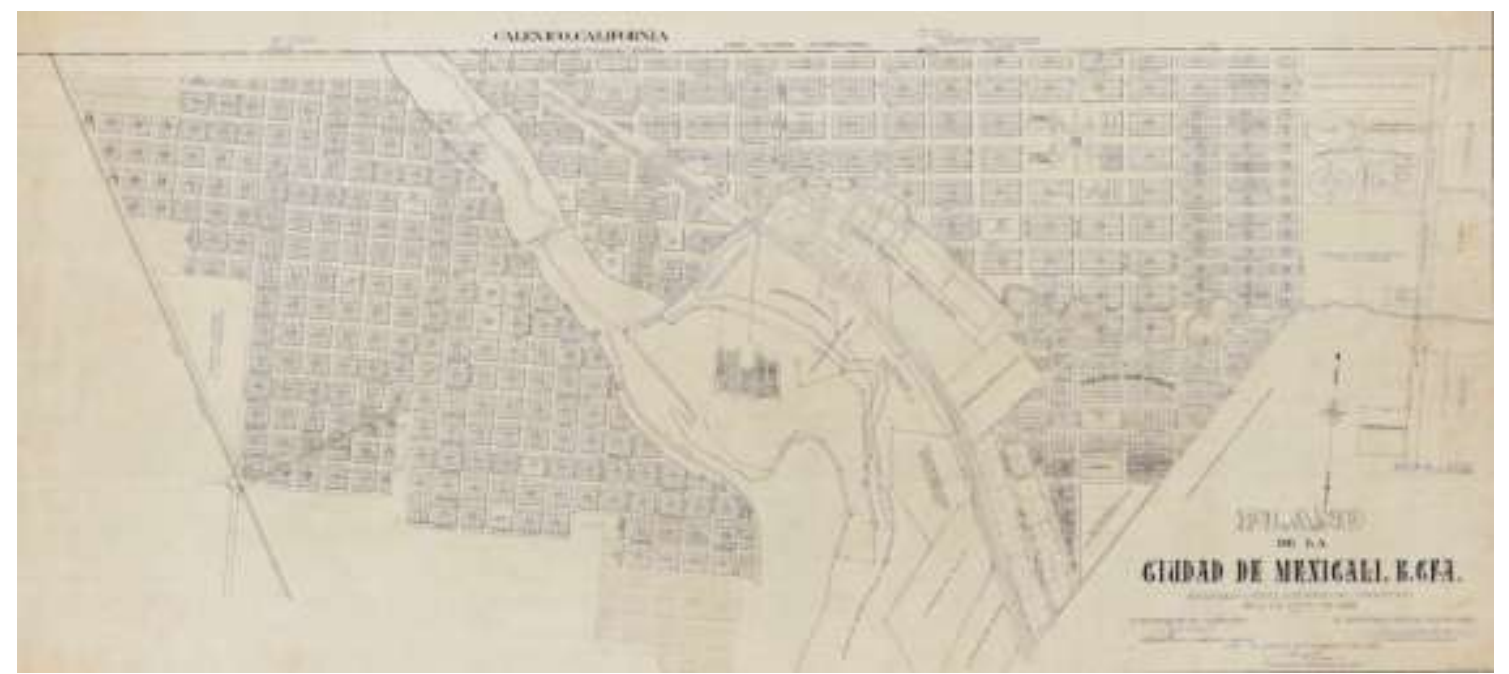

Plano Oficial de la ciudad de Mexicali, 1944. Se aprecia (de izquierda a derecha) el barrio de Pueblo Nuevo, el Río Nuevo y el Primer Cuadro de la Ciudad (Centro Histórico).

Colección Carlos Reyes.

\section{LA PROBLEMÁTICA URBANA ACTUAL EN EL SECTOR CENTRAL}

\section{1 El Centro Histórico}

La entrada en vigor de la Volstead Act (Ley Seca) en 1919, representa un acontecimiento que marcó el crecimiento urbano de Mexicali. Esta ley suscitó que en las ciudades fronterizas con los Estados Unidos de América empezaran a instalarse fábricas y expendios de bebidas alcohólicas, así como negocios afines. Mexicali no fue la excepción, se concentraron en su mayoría en las cercanías del cruce fronterizo, es decir, los primeros cuadros de la ciudad. El corazón de la urbe se transformó en centro de comercio, sobre todo nocturno; la proliferación de anuncios y la creciente edificación de sitios dedicados al espectáculo definió la imagen urbana del poblado. Este pudiera ser considerado como uno de los primeros desplazamientos clave de la ciudad, se movieron algunas viviendas y mudaron las prácticas más domésticas del corazón de la urbe.

Un periodo de crecimiento más acelerado se experimentó iniciados los años cuarenta, cuando un convenio diplomático entre EUA y México, conocido como el Bracero Program, dio entrada a casi cinco millones de mexicanos para laborar en los campos agrícolas de EUA, convirtiendo a la agricultura norteamericana en la más rentable y avanzada del mundo y alterando el medio económico, social y cultural de los asentamientos fronterizos (Durand, 2007). Además, a finales de los años treinta la primera etapa del Ferrocarril Sonora Baja California ya estaba construida, inaugurándose en 1948; esto facilitó la comunicación con el resto del país, incrementando inevitablemente la inmigración hacia la región noroeste de México.

Paralelamente, el valle de Mexicali vivió su momento más próspero: el auge algodonero estaba en su cúspide; por ende, lo que ahora conocemos como sector central se convirtió en la estancia de migrantes que veían oportunidades de empleo o empresa, dándose una importante transformación de este sector pionero de la ciudad. Aunque Mexicali se iba poblando de forma progresiva, y con ello deviniendo de 
poblado a ciudad, desde estos años su centro vivió mudanzas que lo han marcado hasta la fecha: la desaparición latente del uso habitacional.

La Federación, el Estado y el Municipio fueron moviendo sus oficinas sede de los primeros cuadros de la ciudad hacia el nuevo Centro Cívico y Comercial. Este conjunto se ubica desde entonces en lo que fuera un predio industrial cuyas actividades terminaron alrededor de 1960. Puede decirse que este proceso agudizó (e, inclusive, se normalizó) la paulatina e incesante transformación de suelo agrícola en urbano. La conformación de esta nueva centralidad provocó la evidente desocupación de edificaciones emplazadas en los primeros cuadros de la ciudad, la caída de la actividad comercial, el cierre de establecimientos que asistían o complementaban las labores de los administradores públicos y -en general- el desplome de la vitalidad de este sector urbano.

La decadencia del centro tradicional de la ciudad (situación en la que permanece todavía) es ocasionada por una fallida planeación urbana en la que, si bien se conformó un plan maestro que se ocupara del ordenamiento territorial de aquel nuevo Centro Cívico y Comercial y sus reservas aledañas, aparentemente no se contempló la huella que dejaría un desplazamiento tan importante (Peimbert, 2016). Oficios y andanzas tradicionales que daban vida al llamado "pueblo" dejaron huecos aun visibles entre "la calle de las novias", "la calle de las flores", los cines y los cafés.

La novedad frente a la ruina, producto constante de una planeación equívoca en la que desarrollo urbano y segregación se colocan como polos cada vez más opuestos (Lojkine, 1988). Mientras se expandían los límites del área urbana, quedaron predios desocupados que podrían cubrir muchas de las necesidades de territorio actuales, evitando así el deterioro interno de la ciudad y la pulverización urbana. ${ }^{1}$ La construcción de nuevos centros comerciales representó la renovada imagen para zonas baldías limítrofes con el sector central de la ciudad, aunque el centro tradicional se veía cada vez más afectado por los cambios que generaba esta consolidación de nuevos nodos y corredores urbanos. Consumir productos de importación y recorrer largos pasillos dotados de aire acondicionado desplazó el trajinar por los alrededores de la catedral, cuyo entorno vio emerger a los giros rojos como salvación del viejo Mexicali.

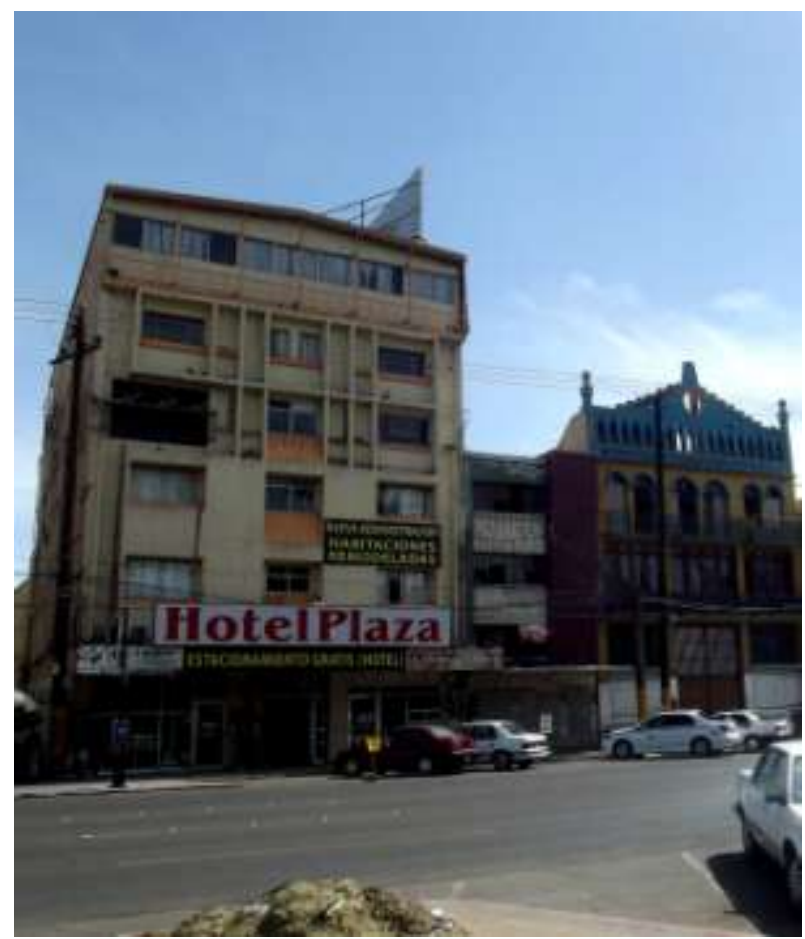

Edificios sobre Av. Madero, calle proveniente de la garita vehicular, situada en el Centro Histórico de Mexicali. Elaboración propia, 2015.

\footnotetext{
${ }^{1}$ De acuerdo con el Instituto Municipal de Investigación y Planeación Urbana (IMIP) el Sur de la ciudad de Mexicali cuenta con población de un nivel socioeconómico medio, el Este con población con nivel socioeconómico medio y alto, y el Oeste y Suroeste con población con nivel socioeconómico bajo, lo anterior se describe con mayor amplitud y detalle en el Programa de Desarrollo Urbano de Centro de Población de Mexicali. Visión 2025.
} 
Hoy, las calles porticadas del centro tradicional se han convertido en una mezcla de paisaje de la nostalgia (Peimbert, 2015) y paisaje del miedo (Lindón, 2007). De día, con el tránsito aun persistente hacia la garita fronteriza se evidencian bajo la pátina del tiempo los vestigios del art déco, del International Style y de la arquitectura californiana. Alternan con construcciones de cartón de yeso que van del pastiche deliberado, al escaparate comercial chocante o a la fachada anodina; también se asoman construcciones ruinosas y pequeños baldíos entre establecimientos comerciales bien consolidados por donde deambulan los migrantes deportados, los indigentes y los avecindados. En este paisaje se mezcla el canto del músico urbano, la voz del vendedor ambulante y los motores que se enfilan para cruzar a la ciudad de Calexico, California. De noche, la prostitución, la indigencia y los añejos estigmas en torno al gueto oriental conocido como La Chinesca, se convierten en los referentes que acompañan el andar de los jornaleros agrícolas que laboran en los campos del Valle Imperial, en el vecino estado de California.

En medio de un panorama nada alentador un colectivo de jóvenes profesionales consolida la iniciativa llamada Algo por el centro, mediante la cual "busca(n) facilitar la planeación, el desarrollo y la ejecución de proyectos de diversa índole para el bienestar del centro histórico [... con la visión de] ser el principal catalizador de iniciativas para el reposicionamiento del Centro Histórico como el corazón de la ciudad" (Algo por el centro, 2016) y, teniendo como ejes rectores los valores de sentido del lugar, diversidad, innovación y cooperación. Este grupo, posicionado como resistencia al abandono por parte de la administración pública, responde en parte a la inercia trienal de todas las alcaldías que han buscado rehabilitar un centro urbano de menos de 100 Has de superficie, sin lograrlo.

\subsection{El Río Nuevo}

La aparición de actividades productivas -justo aquellas que complementaban a la producción agrícola-, la conducción de desechos del rastro, descargas sanitarias de las primeras obras de urbanización y otros establecimientos industriales, empezaron a ocasionar un deterioro del agua del río y su cauce a partir de la década de 1960, llegando a niveles alarmantes en un par de décadas. El problema aun persiste y más del $50 \%$ del agua residual que genera el Municipio de Mexicali se ha estado descargando en el río sin tratamiento alguno (Romero, et al., 2006).

A mediados de la década de 1980 se emprendió un ambicioso proyecto que pretendía recuperar el cauce del Río Nuevo y habilitar sus espacios como un gran parque; solamente llegó a concretarse la remodelación de una unidad deportiva. Fue hasta finales del siglo XX cuando se empezaron a ver realizadas ciertas acciones de mayor impacto. El abovedado del río se acompañó con la construcción de una amplia vialidad llamada Calzada de los Presidentes, o Bulevar Río Nuevo, esto trajo como resultado el inicio de la construcción de equipamiento de diversa índole, que paulatinamente ha incidido en la modificación de la imagen urbana del lugar: el Centro de Ferias, Eventos y Exposiciones FEX, en 2001; la Plaza Centenario y el acceso oriente al Bosque de la ciudad en 2003; el Centro Estatal de las Artes en 2005; el inmueble de la Facultad de Ciencias Administrativas de la UABC en 2007; el edificio de la Procuraduría General de Justicia del Estado en 2010, entre otras. Todo ello ha conformado un área aun de desarrollo difuso en toda su extensión, y esta se define en alrededor de $9 \mathrm{~km}$ de la calzada.

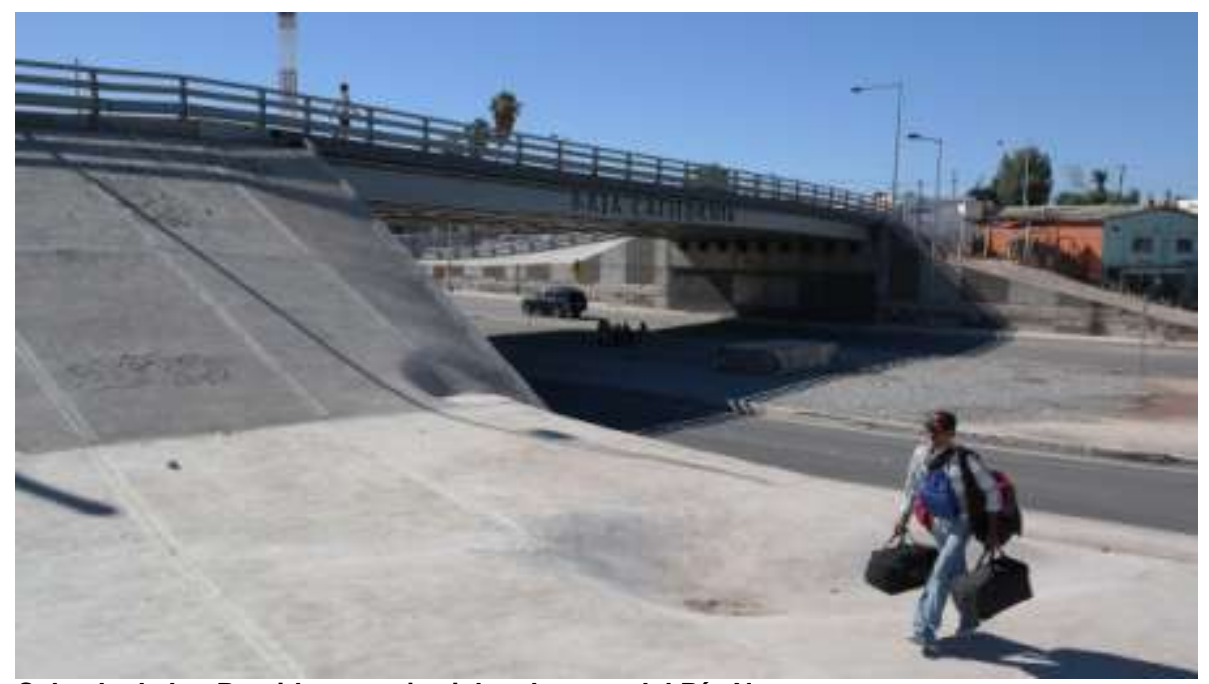

Calzada de los Presidentes, eje vial en la zona del Río Nuevo.

Elaboración propia, 2013. 
Desde su origen, esta zona se ha caracterizado por exponer en sus espacios públicos una latente tensión entre grupos de poder y grupos contra-hegemónicos. Esta confrontación se percibe desde el imaginario hasta en las prácticas cotidianas. La Plaza Centenario es uno de los sitios que mayormente advierte el desencuentro entre lo que es un espacio público, lo que la gente hace en él, y lo que el gobierno quiere que sea. La rotonda con un asta bandera monumental y un mural artístico que reseña la historia de la ciudad se pensaría no solo como espacio que celebra la patria, sino como un lugar de encuentro, de manifestación de ciudadanía y de expresión de lo público.

Esta condición del río se remonta a sus orígenes. Debido a su topografía -pese a su ubicación- se convirtió en un espacio residual. Fue asentamiento de personas de escasos recursos económicos que formaron barriadas, reubicadas en varios periodos del gobierno estatal, debido a las inundaciones que causan las lluvias invernales intensas; de estos asentamientos subsisten un par de colonias que siguen padeciendo los efectos de las tormentas que suelen azotar eventualmente a la ciudad y del desbordamiento de aguas negras cuando el cauce canalizado del río se desborda.

Después del fuerte temblor que afectó Mexicali en el año 2010 se reveló un peligro latente, propicio para contemplar la reubicación de estos asentamientos irregulares. Esto se expresó con mayor insistencia a finales de 2011, cuando el gobernador José Guadalupe Osuna Millán y el alcalde Francisco Pérez Tejada coincidieron en contemplar como algo inminente la reubicación de estas dos colonias (Mercado, 2011). La percepción del riesgo se yuxtapone con la de zona de promesa.

\subsection{Pueblo Nuevo}

El barrio de Pueblo Nuevo está constituido por un grupo de colonias dispuestas al poniente del río Nuevo, entre ellas Loma Linda, Santa Clara, Revolución, Orizaba y, de mayor dimensiones, la colonia con el mismo nombre. Aunque administrativamente se diferencian por demarcaciones catastrales, el imaginario colectivo de los residentes y el resto de la comunidad mexicalense lo conciben como un solo tejido urbano y social. Esta zona ocupa una proporción importante en el total del área urbana, las cinco colonias suman aproximadamente 360 ha. de superficie.

La urbanización de dicho barrio se dio de manera pausada, presumiblemente por tratarse de un asentamiento de clase popular y -por ende- no entrar en las prioridades de la agenda desarrollo urbano. Un elemento clave para la dotación de servicios públicos fue la organización y colaboración de la comunidad de vecinos pioneros que lo integra. Esto lo demuestran los distintos comités (Güicho, 1999) que desde la fundación del barrio laboraron a favor de la implementación de infraestructura. Inicialmente, con la edificación de puentes vehiculares y peatonales sobre el Río Nuevo para unir este barrio con el centro de la ciudad. Conforme el barrio fue aumentando su población, las necesidades comenzaron a ser cada vez más apremiantes, por lo que estos grupos vecinales se reconstituyeron para la gestión del alcantarillado público. Finalmente, destacan las labores para pavimentar calles y callejones.

Lo mismo sucede con la creación de equipamiento. Ciertos elementos del equipamiento urbano del lugar, se han hecho representativos al barrio, constituyéndose como auténticos hitos. Por ejemplo, la Iglesia de San Antonio; la Escuela Primaria Pública Netzahualcóyotl; el tanque de agua elevado; la Unidad Deportiva y la Estación de Bomberos (estos tres últimos emplazados en el mismo conjunto). Además, distintos establecimientos comerciales se hicieron populares, definiendo con ello dos corredores que logran intersectarse: la calle 3ra (Uxmal) y la avenida Michoacán.

Actualmente se registra una disminución en la densidad poblacional del barrio, así como un aumento en la cantidad de predios baldíos, viviendas abandonadas y comercios cerrados. Tres factores que inciden en dicho despoblamiento son: las políticas nacionales de vivienda de interés social, que particularmente en el caso de Mexicali, han provocado un desplazamiento de las zonas habitacionales del centro hacia la periferia; la localización relativa del barrio, ya que los principales recintos laborales, comerciales y recreativos de la ciudad se encuentran cada vez más "distantes" del sector central, conformándose una ciudad fronteriza poli-céntrica; por último, la relación de dependencia económica-laboral con los Estados Unidos de América ha propiciado una incesante emigración de un importante número de familias. 


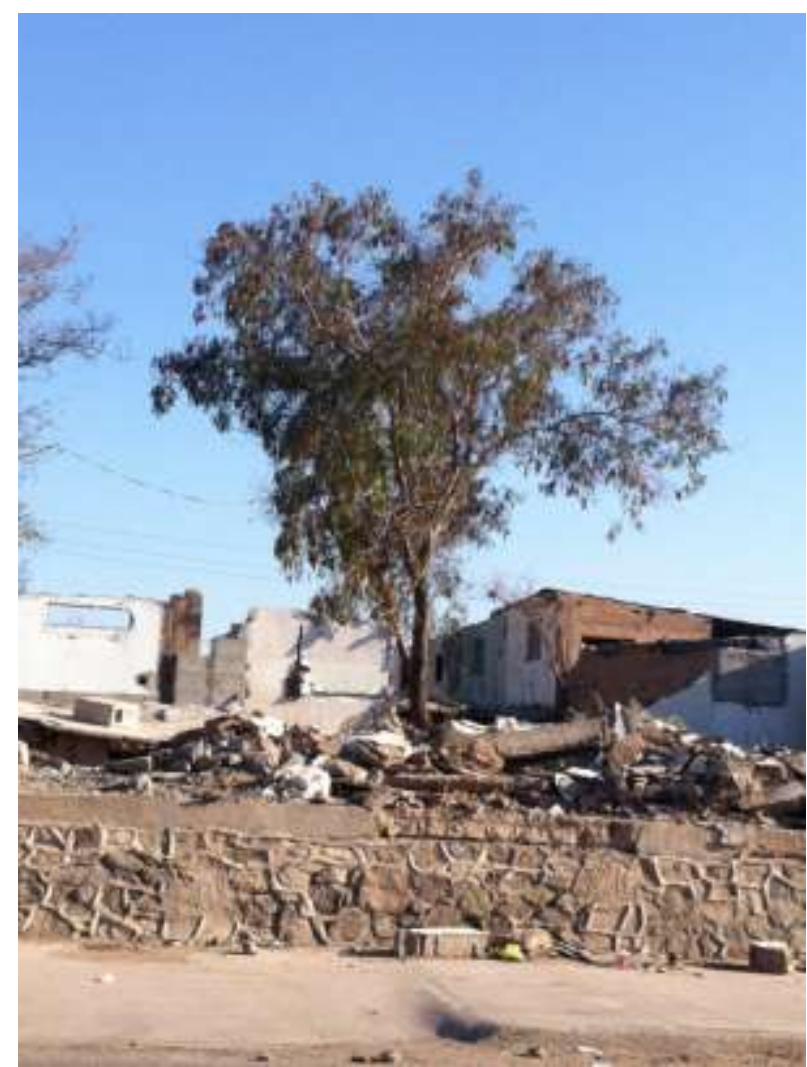

Aspecto actual del deterioro en el barrio de Pueblo Nuevo. Elaboración propia, 2017.

Estos procesos han propiciado cierta incertidumbre en torno a la tenencia del suelo y, con ello, la invasión de inmuebles por parte de indigentes, migrantes deportados y familias desplazadas del sur del país o del continente. Además, destaca el registro de un alto índice delictivo, en comparación con otras colonias de la ciudad. Ello aumenta la ya implantada estigmatización de la zona, disminuyendo las posibilidades de cohesión social que antes se mostraban y que -incluso- caracterizaban a Pueblo Nuevo. Hoy en día, los nuevos pobladores no muestran sentido alguno de pertenencia con el barrio, como lo conservan los descendientes de los pioneros que aun residen ahí.

\section{POLÍTICAS APLICADAS: EL FENÓMENO AISLADO}

El análisis morfológico del tejido fundacional de Mexicali no tendría por qué detenerse en la revisión de los aspectos que atañen a la ciudad construida. Considerar el marco de la planeación permitirá, en este estudio, identificar de qué modo responden las políticas de desarrollo urbano a la problemática de las zonas ya mencionadas. Indudablemente, los planes y programas se han referido a estas, en especial al Centro Histórico y al Río Nuevo. No obstante, aquí se destaca que ningún instrumento las observa de forma conjunta, aun con la innegable correlación que existe entre las tres zonas que conforman el sector del que se ocupa este texto.

El Programa de Desarrollo Urbano del Centro de Población de Mexicali (IMIP, 2007), no contempla a la Zona Centro, al Río Nuevo, ni el barrio de Pueblo Nuevo como un conjunto interrelacionado. Así, aunque toma en cuenta las particularidades y problemáticas de cada una de ellas en la elaboración de un diagnóstico-pronóstico y en la definición de propuestas a nivel normativo, estratégico e instrumental, estas tres zonas aparecen como conjuntos independientes.

Cabe señalar que para este $P D U C P$, el término zona central hace referencia al área urbana que se forma entre el Centro Histórico y el Centro Cívico, conectado precisamente por el Río Nuevo (así como por el Blvd. López Mateos), espacios que integran en mayor medida las actividades económicas, así como el equipamiento cívico y de esparcimiento en la ciudad. Sin embargo, el uso de suelo habitacional no tiene cabida en esta visión de la ciudad. Por ello el barrio de Pueblo Nuevo es considerado en el PDUCP como un subcentro de la ciudad, así al clasificar estas áreas como corredor (Río Nuevo), centro (zona histórica) y subcentro (Pueblo Nuevo); las estrategias de acción tienden a polarizarse y no a procurar una integración. 
Esta disgregación de las zonas fundacionales de Mexicali, se denota con mayor claridad en la elaboración de programas parciales o sectoriales, entre los cuales se encuentra el Programa Parcial de Desarrollo Urbano del Río Nuevo (XV Ayuntamiento de Mexicali, 1997). Este, con una serie de actualizaciones pendientes, tiene como objetivos el "incorporarlo al desarrollo urbano de la ciudad, mejoramiento de la calidad de vida de la población, [así como el] establecimiento de patrones más eficientes de funcionalidad urbana y la definición de una imagen de la ciudad inclusiva".

Este programa parcial limita su rango de influencia al propio barranco del Río Nuevo: "la definición de colonias no necesariamente incluye a la colonia en su totalidad, por el contrario, fue seleccionada el área específica para que coincidiera con la zonificación de AGEB's" (XV Ayuntamiento de Mexicali, 1997). ${ }^{2}$ Al mismo tiempo que admite que "en la actualidad no cuentan con instrumentos de planeación que considere un enlace. Por ello la necesidad de establecer un área de transición entre el Río Nuevo y la unidad territorial adyacente" (XV Ayuntamiento de Mexicali, 1997).

Es decir, el programa parcial pretende favorecer la integración de diversos sectores de la ciudad, pero sin llegar a profundizar en la incidencia y reciprocidad de esta área con los espacios más próximos:

Su configuración con relación a la ciudad es la de un borde físico que determina una discontinuidad de dos grandes áreas de la ciudad: ausencia de una estructura urbana del río Nuevo. Al norte tiene menor discontinuidad. Una de las acciones de mejoramiento más importantes consiste en la integración del río Nuevo a la estructura urbana propuesta de la ciudad de Mexicali. La solución vial del río Nuevo será el elemento más importante para lograr esa integración; pero la definición de usos del suelo y sus características, así como las determinaciones de desarrollo urbano de las áreas aledañas en su vinculación a las áreas desarrollables del río, serán el elemento que complemente finalmente la integración funcional del río Nuevo. (XV Ayuntamiento de Mexicali, 1997)

Ahora bien, el PDUCP vigente establece la relación entre estas tres áreas de estudio a partir de dos características determinantes: imagen urbana y riesgos y vulnerabilidad.

Los distritos o zonas homogéneas que presentan una imagen deteriorada se encuentran principalmente en la zona central, y en las zonas populares en la periferia oeste y sur de la ciudad, así como fraccionamientos irregulares, dentro de los cuales se encuentran: zona Centro, zona del Río Nuevo [...] Pueblo Nuevo-Loma Linda [entre otros]. (IMIP, 2007)

Pero aun con ello, las estrategias y proyectos continúan desarrollándose de manera sectorial:

Los núcleos urbanos (Centro Histórico y Centro Cívico) mantienen una tendencia de deterioro económico y físico que se ha recrudecido con el incremento de las actividades informales e ilícitas, la falta de mantenimiento a la infraestructura y la desatención del espacio público. (IMIP, 2007)

Llama la atención que, respecto al Centro Histórico de Mexicali aun y con varios estudios y proyectos elaborados tanto por co-dependencias locales, instituciones educativas, o por empresas consultoras, no se ha visto ningún programa parcial, programa sectorial, ni proyecto de rehabilitación publicado de forma oficial, es decir, con validez normativa. Entre ellos se cuentan el Estudio de Reactivación Económica y Urbana del Centro Histórico de Mexicali, B.C. (UABC - CEDEM, 2000); Programa Parcial de Mejoramiento del Centro Histórico y Comercial de Mexicali, B.C. (IMIP, 2006); y el Proyecto de Revitalización del Centro Histórico de Mexicali (XVIII Ayuntamiento de Mexicali - HABITAT - Uro y Asociados, S.A de C.V., 2008). Sin la debida implementación de los planes y proyectos correspondientes, poco pudiera concretarse respecto al centro de la ciudad, menos aun sobre los dos ámbitos vecinos a que nos referimos en este texto.

\footnotetext{
${ }^{2}$ De acuerdo al Instituto Nacional de Estadística y Geografía, un área geo-estadística básica (AGEB) es la extensión territorial que corresponde a la subdivisión de las áreas geo-estadísticas municipales. En el ámbito urbano está definida por conjuntos de manzanas, generalmente de 1 a 50 y se encuentran delimitadas por calles, avenidas, andadores o cualquier otro rasgo fácil de identificar en el terreno y cuyo uso del suelo sea principalmente habitacional, industrial, de servicios y comercial. (INEGI, 2010)
} 
En 1995 se creó la iniciativa municipal del denominado Proyecto Zona Centro (PROCENTRO), dependencia encargada de implementar soluciones para abatir el deterioro físico y de la imagen urbana de esta zona. No obstante, en aras de emprender acciones centradas en el aspecto estético de las calles, espacios abiertos y edificaciones con valor histórico del centro de la ciudad, se fueron descuidando aspectos que inciden de forma importante en el desarrollo urbano, tales como el declive en la economía, las problemáticas socioculturales y las condiciones políticas desfavorables que inhiben toda acción de mejora sobre un centro urbano.

Las propuestas derivadas de PROCENTRO se fueron turnando al Instituto de Investigación y Planeación Urbana de Mexicali (IMIP), organismo municipal descentralizado con personalidad jurídica, patrimonios propios y con autonomía técnica, a través del cual se diseñan, coordinan, promocionan e instrumentan las políticas, planes y programas de desarrollo urbano de Mexicali. Así, el IMIP ha concebido una serie de proyectos estratégicos que inciden en el mejoramiento de la imagen urbana, como el caso del Centro Cívico y Comercial de la Ciudad de Mexicali, el de Reactivación Urbana de la Zona del Río Nuevo, el de Mejoramiento de Barrios, entre otros. De estos, se han desprendido algunas acciones más específicas y, aunque forman parte de una misma entidad, el nivel y el ámbito de acción no logra impactar a una escala de integración entre el Centro Histórico, Pueblo Nuevo y el Río Nuevo.

Después de cinco periodos administrativos (lo que equivale a casi dos décadas), fue desintegrado PROCENTRO. Sus logros se centraron en una serie de soluciones puntuales y, en general, en asentar el reconocimiento y dimensionamiento por parte de diversos grupos (vecinos, empresarios, profesionales de la arquitectura y el urbanismo, etc.), de la existencia de una zona problemática con aristas muy complejas. Los conflictos esenciales prevalecen. Ahora, el proyecto ciudadano conocido como Mexicali Gran Visión, creado en el año 2013, es el organismo que ha asumido la iniciativa en torno al desarrollo urbano, ambiental y económico no solamente del Centro Histórico de Mexicali, o de la ciudad entera, sino de las seis grandes áreas que contempla el territorio municipal.

Mexicali Gran Visión funciona bajo el esquema de la planeación participativa, con una importante injerencia de la iniciativa privada (en especial del sector empresarial). Hasta el momento, su trabajo se ha concentrado en tres planes: Plan Estratégico Municipal de Mexicali 2015-2029 (UABC - CDEM, 2011), la actualización del Plan Municipal de Desarrollo 2015-2050 (UABC - CDEM, 2013) y Plan Estratégico Metropolitano 20152050 (UABC - SIDUE, 2012), todos ellos publicados con el fin de facilitar la gestión municipal y la participación de la comunidad en sus propósitos de desarrollo. Es en este marco en el que podrían darse las acciones esperadas para el tejido urbano fundacional de Mexicali.

Finalmente, el Plan Estratégico Municipal de Mexicali 2015-2029 (UABC - CDEM, 2011) se menciona de forma general, dentro del apartado dedicado al desarrollo urbano y rural, acciones que apuntan hacia la imagen urbana así como hacia la gestión. Específicamente, se expone en el programa de acciones "Promover la Regeneración de Accesos a la Ciudad, Corredores y Centros Urbanos". En esto pudieran verse incorporadas dos de las tres zonas que aquí se estudian. No obstante, el barrio de Pueblo Nuevo parece no incluirse en iniciativa alguna de este instrumento.

Mientras tanto, en la actualización del Plan Municipal de Desarrollo 2015-2050 (UABC - CDEM, 2013), se aborda un aspecto relevante para el caso de estudio que aquí se presenta. En el apartado Administración del desarrollo urbano y -en específico- en el inciso correspondiente a las Áreas y sectores estratégicos del desarrollo urbano, se identifica a la revitalización y el desarrollo de áreas internas de las ciudades como parte de un desarrollo urbano ordenado. En este ámbito se incluye el barrio de Pueblo Nuevo; evidentemente, como parte de un sector histórico, cultural y socialmente significativo de la ciudad. Al respecto, este instrumento enuncia lo siguiente:

Es posible identificar dentro del municipio áreas que requieren la revaloración de su funcionalidad o la reposición de la infraestructura y el equipamiento urbano con el propósito de absorber las nuevas funciones que la estructuración urbana del centro de población le tiene asignada. [... Se trata de] áreas deterioradas que son un obstáculo a la comunicación y desaprovechan una de las áreas estratégicas de la ciudad cuyo pasado ha perdido todas las condiciones de un desarrollo armónico y competitivo. [...] La revitalización es estratégica; tiene un impacto en el desarrollo económico y permite la integración de áreas que optimizan el crecimiento y la productividad de la ciudad al disminuir la necesidad de una expansión ilimitada. Incluye en este subregión una de las áreas de más abolengo y tradición de la ciudad, Pueblo Nuevo. [...] El modo de crecimiento se conceptúa a partir de los beneficios económicos y de funcionalidad urbana a partir de una densificación y 
revalorización de un suelo que presenta excelentes cualidades de localización con deficientes parámetros de calidad urbana en la infraestructura urbana y la edificación que promueven una imagen urbana deficiente. (UABC - CDEM, 2013)

Con esto se esperaría la implementación de acciones concretas, en un mediano plazo, sobre el sector central. Aunque, ciertamente, en los últimos años se ha visto privilegiada la inversión pública y privada hacia el sector noreste de Mexicali, especialmente en la llamada comúnmente "Zona Dorada". Se trata de una zona calificada como de estrato económico medio-alto, y está conformada básicamente por comunidades habitacionales cerradas (algunas de ellas las de mayor valor en la ciudad), centros comerciales, colegios privados (de los distintos niveles educativos) y con una serie de reservas inter-urbanas que han venido a albergar en los últimos años edificios verticales de usos mixtos, tipología que no se había dado en la ciudad.

\section{CONCLUSIONES}

Analizar la morfología del tejido urbano fundacional de Mexicali, hoy sector central, condujo a identificar qué se ha abordado u omitido desde el marco institucional y a partir de los distintos instrumentos de planeación urbana. Esta revisión documental se fundamenta en la relevancia que tiene la conexión entre el Centro Histórico, la zona del Río Nuevo y el barrio de Pueblo Nuevo. Es evidente que esta conexión ha sido suprimida en los estudios y proyectos emanados por el gobierno, sus dependencias y las instituciones descentralizadas del mismo.

El vínculo entre las tres zonas, no solamente se hace patente en su estructura urbana, sino que se da en otras escalas, dimensiones y ámbitos. Es pertinente subrayar aquí los aspectos potenciales de este vínculo, como puntos concluyentes encaminados a tratarse como recomendaciones. Los estudios y proyectos que se ocupen de estas zonas tendrían que considerar a estas tres zonas constituidas como un transecto urbano. Toda acción o inercia que incida en alguna de ellas o en su totalidad tendrá -inevitablementeimplicaciones en su entorno inmediato. En el mejor de los casos, los puntos que se presentan a continuación se pueden tratar como las pautas para un esquema de integración urbano-paisajística del sector central de Mexicali.

Las relaciones socio-espaciales dentro de las tres zonas que integran el tejido urbano fundacional de Mexicali son parte esencial de su funcionamiento. El recurrente tránsito de residentes de Pueblo Nuevo y su cruce sobre el bulevar Río Nuevo para dirigirse al Centro Histórico, ya sea para ir a los Estados Unidos o para tomar algún transporte público que los dirija a otro sector de la ciudad, no solo define sendas claras que eslabonan a las zonas, sino que propicia interacciones significativas entre el origen y el destino. En estas relaciones socio-espaciales se asoman dinámicas cuya escala no pareciera trascendente, pero que potencian nuevos usos del suelo, pluralizan fuentes de empleo y rompe estigmas añejos. No obstante, también revela distintos grados de exclusión e inaccesibilidad hacia lo público y lo universal.

Las prácticas asociadas a la vida cotidiana como la ocupación provisional de las aceras -particularmente en el Centro Histórico y en Pueblo Nuevo- solamente para estar, o para ver pasar, definen este ámbito como lugar de contacto con el otro y con lo otro, lo que da sentido al espacio público. Habría que inhibir usos o destinos del suelo que violenten esta forma de habitar; es decir, evitar la privatización de las aceras. El Río Nuevo habrá de trascender como sitio de pasos apresurados para presentarse -al menos un sus segmentos más cercanos al Centro Histórico y Pueblo Nuevo- como el gran concentrador del esparcimiento y el ocio, del arte y el deporte.

La historia del tejido urbano y los vestigios arquitectónicos que en las tres zonas aun se conservan representan un asunto de suma trascendencia para concebir esta integración. Cada zona presenta sus propias características respecto al trazo y a sus tipologías edificadas.

Del Centro Histórico habrá que considerar su estructura urbana dirigida al comercio y los servicios, con vías que exponen, además del origen de la ciudad, la posición de un nodo primario: el cruce fronterizo. La tipología de la edificación porticada produce una percepción sui generis del espacio de la calle y define una transición -de lo vehicular a lo peatonal- que valdría replicar en otros sectores de Mexicali. El Río Nuevo, paisaje intersticial desde su aparición en el territorio (Peimbert, 2016), cuenta con el potencial de un gran parque lineal. Además de consolidarse como conjunto de equipamiento tendría que ordenarse como un sistema de espacios abiertos que articulen el tránsito agresivo desde Pueblo Nuevo hacia el Centro Histórico; pensarlo como un gran paisaje que incorpore infraestructura, espacio públicos y edificaciones de 
usos mixtos, conservando estratégica y moderadamente su condición intersticial para que en sus vacíos quepan espacios ajardinados libres, como pulmones urbanos.

Para el barrio de Pueblo Nuevo la vivienda representa no solo su génesis, sino la alternativa más apropiada para densificar. Pero, se debe pensar la densificación diversificada en tipos, dimensiones, horizontes de planeación e -incluso- estratos socioeconómicos. Al mismo tiempo, tendrá que revalorarse que este barrio aloja una serie de oficios tradicionales -tanto dependientes como derivados del uso habitacional- que permanecen vigentes y que se podrían multiplicar en virtud de consolidar la centralidad y función de este tejido fundacional.

La recuperación de este tejido urbano fundacional como sector central no podría evadir fenómenos socioculturales recurrentes u oscilantes en ciertos entornos urbanos fronterizos, tales como la migración, la violencia y las políticas de gentrificación. Habrá que contemplar los equipamientos y mecanismos para atender tanto a sujetos desplazados de forma forzada o migrantes deportados; habrá que identificar los ámbitos en que se manifiesta la violencia (en sus distintos tipos) que opera en especial sobre los sujetos más vulnerables; habrá que anular toda acción que, en virtud de reactivar una zona, propicie la mudanza de residentes pioneros, la especulación inmobiliaria y la atomización de fuentes de trabajo existentes.

\section{REFERENCIAS}

ÁLVAREZ, G. y PADILLA A. (2011). El Río Nuevo, la línea Fronteriza y el ferrocarril, su impacto en la forma urbana. Revista Semillero, 74, 28-42.

CAPEL, H. (2002). La morfología de las ciudades: sociedad, cultura y paisaje urbano. Barcelona: Ediciones del Serbal.

DURAND, J. (2007). El Programa Bracero (1942-1964). Un balance crítico. Migración y Desarrollo, 9, 27-43.

GÜICHO, F. (1999). Y nació Pueblo Nuevo. Mexicali: Instituto de Cultura de Baja California.

IMIP, Instituto Municipal de Investigación y Planeación Urbana (2007). Programa de Desarrollo Urbano del Centro de Población de Mexicali. XVIII Ayuntamiento de Mexicali.

(2006). Programa Parcial de Mejoramiento del Centro Histórico y Comercial de Mexicali, B.C.

JACOBS, J. (1961). Muerte y vida de las grandes ciudades. Madrid: Capitan Swing.

LINDÓN, A. (2007). La construcción social de paisajes invisibles y del miedo. En J. NOGUÉ (ed.), La construcción social del paisaje (213-236). Madrid: Biblioteca Nueva.

LOJKINE, J. (1988). De la política estatal a la política urbana: el papel del Estado en la urbanización capitalista. En M. BASSOLS y R. DONOSO (comps.), Antología de sociología urbana (527-576). México: Universidad Nacional Autónoma de México.

LYNCH, K. (2005). Echar a perder, un análisis del deterioro. Barcelona: Gustavo Gili.

PEIMBERT, A.J. (2015). Etnografía de una inseguridad invisibilizada. Ciudades, 105, 23-28.

(2016). Paisaje intersticial: vacíos y ruinas en el arte, la arquitectura y la ciudad. Mexicali: Universidad Autónoma de Baja California.

REYES MORENO, C. M. (1985). La zona del Río Nuevo como elemento de integración urbana entre el primer cuadro de la ciudad y la colonia Pueblo Nuevo. (Tesis de licenciatura). Universidad Autónoma de Baja California. Mexicali.

ROBLES, C. (2009). La arquitectura de Mexicali: orígenes. Mexicali: Universidad Autónoma de Baja California.

ROMERO, S. et. al. (2006). El aprovechamiento del agua residual tratada: una alternativa hacia la sustentabilidad del agua en la región fronteriza Mexicali, México-Imperial, EUA. En M. QUINTERO 
(ed.), Contaminación y medio ambiente en Baja California (177-200). Mexicali: Universidad Autónoma de Baja California.

UABC - CEDEM (2000). Estudio de Reactivación Económica y Urbana del Centro Histórico de Mexicali, B.C.

UABC - CDEM (2011). Plan Estratégico Municipal de Mexicali 2015-2029. Mexicali Gran Visión.

UABC - SIDUE (2012). Plan Estratégico Metropolitano 2015-2050. Mexicali Gran Visión.

UABC - CDEM (2013). Plan Municipal de Desarrollo 2015-2050. Mexicali Gran Visión.

VERDUGO, I. (2007). Las colonias urbanas de Mexicali. En M. OLAZABAL y A. RODRíGUEZ (coords.), Memoria histórica de Mexicali: la ciudad que capturó al sol (77-87). Mexicali: XVIII Ayuntamiento de Mexicali.

WALTHER, A. (1991). El origen de Mexicali. Mexicali: Universidad Autónoma de Baja California. (2000). Pueblo Nuevo, poblado precursor. Mexicali: Universidad Autónoma de Baja California.

XV Ayuntamiento de Mexicali (1997). Programa Parcial de Desarrollo Urbano del Río Nuevo. Mexicali, B.C. Periódico Oficial del Estado de Baja California.

XVIII Ayuntamiento de Mexicali - HABITAT - Uro y Asociados, S.A de C.V. (2008). Proyecto de Revitalización del Centro Histórico de Mexicali.

\section{Fuentes electrónicas:}

MERCADO, J. (2011, diciembre 16). Reubicarán El Vidrio y Agualeguas. La Voz de la Frontera. Mexicali. Recuperado a partir de http://www.oem.com.mx/lavozdelafrontera/notas/n2350693.htm (Consulta: 10/11/2016). 